\title{
Estrategias para combatir enfermedades producidas por la emergencia de resistencia a antibióticos
}

\section{Strategies to combat antibiotic resistance}

ARTÍCULO

\author{
María Belén Pastrian \\ Secretaría de Ciencia, Tecnología e Innovación Productiva de Chubut, Argentina. \\ Contacto: mbpastrian@gmail.com
}

Recibido: marzo de 2018

Aceptado: mayo de 2018

\begin{abstract}
Resumen
La emergencia de bacterias resistentes a los antibióticos presenta un importante problema en la actualidad, que se cobrara más de 10 millones de vidas en el 2050 si no se soluciona a tiempo. Una manera de atacar el problema es mediante el desarrollo de nuevas entidades antimicrobianas cuyo blanco de acción sea un componente celular difícil de modificaro reemplazar, para generar resistencia, constituye un hallazgo de gran valor para la medicina y la industria farmacéutica. Los péptidos KW-arilados son excelentes IFAs para el desarrollo de formulaciones farmacéuticas antimicrobianas. Son entidades peptídicas novedosas porque fueron desarrolladas racionalmente a partir de un fragmento (107RKWVWWRNR115) de la lisozima humana por arilación de sus residuos de triptófano (Trp), lo que produjo un efecto positivo sobre la inhibición del crecimiento de Staphylococcus aureus y Staphylococcus epidermidis. Se accedió a esta modificación selectiva del sitio por síntesis de péptidos en fase sólida (Kates, 2000) utilizando el aminoácido no proteinogénico 2-ariltriptófano, generado por activación directa de $\mathrm{C}-\mathrm{H}$ a partir de Trp protegido. La modificación provocó un aumento relevante en la inhibición del crecimiento: S. aureus se inhibió completamente por arilación de Trp 112 y solo por $10 \%$ por arilación de Trp 109 o 111, con respecto al péptido no arilado. Por otro lado, S. epidermidis se inhibió completamente por los tres péptidos arilados y el péptido original. La concentración mínima inhibitoria se redujo significativamente para S. aureus dependiendo del sitio de arilación.
\end{abstract}

Palabras clave: péptidos antimicrobianos; lisozima humana; arilación de triptófanos.

\section{Abstract}

The increase in the antimicrobial resistance makes a great threat to the world population and has been recognized by organizations such as the United Nations and World Health Organization. One way to attack this problem is the development of new molecules for the treatment of infectious diseases. Antimicrobial peptides (AMPs), also known as host defense peptides, are short and generally positively charged peptides found in a wide variety of life forms from microorganisms to humans. We have designed and developed antimicrobial peptides with potent antimicrobial activity against a broad spectrum of bacteria including Staphylococcus aureusmethicillin-resistant with no adverse hemolytic activity. KW-arilated are 3 nonapeptides derivatives of fragment 107-115 of the human lysozyme and present 3 modifications with respect to the leader sequence that increased their antimicrobial activity. The arylation of the Trp was carried out on carbon 2 with a phenyl group with the aim of increasing its anchoring capacity to the bacterial membrane. This therapeutic target implies a difficult development of resistance on the part of microorganisms.

Keywords: antimicrobial activity; human lysozyme; arylation; tryptophan; antibiotic resistance. 


\section{¿Se han preguntado por qué enfermedades que eran parte del pasado han resurgido en la actualidad?}

La resistencia a los antibióticos constituye, en la actualidad, una de las mayores amenazas para la salud a nivel mundial. Se estima que para el año 2050 la resistencia a los antibióticos presentará un escenario devastador. Como informa Jim O'Neill (2016), ex presidente de la Review on Antimicrobial Resistance, actualmente se producen 700.000 muertes por infecciones resistentes a fármacos vaticinando que se convertirían en 10 millones para la década del 50 , es decir, más personas que las que mueren de cáncer.

Los antibióticos son herramientas muy útiles para tratar infecciones y aunque su excesivo e indiscriminado uso genere resistencia, se trata de un proceso evolutivo natural que ha provocado la emergencia de bacterias multirresistentes a los antibióticos.

El manejo terapéutico de las infecciones causadas por microorganismos multirresistentes es cada vez más difícil debido al agotamiento de las alternativas antibióticas. En este contexto, la Organización Mundial de la Salud (OMS), convoca a la comunidad científica y a las empresas farmacéuticas a los fines de aunar esfuerzos en pos del desarrollo de nuevos agentes antimicrobianos que amplíen el arsenal terapéutico para poder responder a este fenómeno a generarse en las próximas décadas.

Resulta fundamental diseñar y desarrollar nuevas entidades cuyo blanco de acción sea un componente celular difícil de modificar o reemplazar para generar resistencia, lo cual constituiría un hallazgo de gran valor para la medicina y la industria farmacéutica.

La comunidad científica ha focalizado su atención en los péptidos antimicrobianos (AMPs) a fin de obtener agentes con aplicación en la producción de alimentos y como agentes terapéuticos. Esto sumado al hecho de que existe poca evidencia de la resistencia microbiana a los AMPs (Peschel, 2006), los convierte en moléculas con gran potencial para su uso como antibióticos. En la actualidad, se conocen más de 2.000 AMPs y su caracterización ha demostrado que la gran mayoría de estos péptidos son catiónicos (péptidos con carga neta positiva).

En este contexto, el fragmento 107 a 115 del extremo C-terminal de la lisozima humana (hLz) posee una actividad antimicrobiana significativa (lannucci, 2013). En función de lo expuesto se llevó a cabo un trabajo conjunto entre investigadores argentinos (UNQ, UBA y CONICET) y españoles de la Universidad de Barcelona en el que se diseñaron nuevos péptidos que podrían representar excelentes Ingredientes Farmacéuticos Activos (IFAs) para el desarrollo de formulaciones antimicrobianas (González R, 2016), mediante la aplicación de una estrategia novedosa de arilación de péptidos desarrollada por la Universidad de Barcelona con el fin de mejorar la actividad antimicrobiana intrínseca del péptido (Ruiz-Rodríguez J, 2010).

Estos péptidos, denominados momentáneamente KW-Arilados, son péptidos de 9 aminoácidos cuya producción industrial por síntesis química es económicamente rentable. 
Los potenciales mercados para este desarrollo son las empresas farmacéuticas nacionales y/o internacionales interesadas en responder a la demanda de nuevas entidades antimicrobianas.

Los KW-Arilados son 3 nonapéptidos derivados del fragmento 107-115 de la hLz. Presentan 3 modificaciones respecto a la secuencia líder que aumentaron su actividad antimicrobiana. En la posición 108 se sustituyó la alanina por lisina (Alax Lys), en la posición 111 se sustituyó la alanina por un triptófano (Ala x Trp) (lannucci, 2013) y se arilaron secuencialmente los 3 Trp de la molécula ubicados en las posiciones 109, 111 y 112 (Rodríguez, 2016). La arilación de Trp se realizó en el carbono 2 con un grupo fenilo con el objetivo de aumentar su capacidad de anclaje en la membrana bacteriana.

La siguiente tabla muestra las secuencias del péptido líder, la secuencia intermedia $\mathrm{K}^{108}-\mathrm{W}^{111} 107-115 \mathrm{hLz}$ y los tres péptidos arilados, cada uno con un Trp-fenilo respectivamente:

\begin{tabular}{|c|c|c|}
\hline Secuencia & Formula & Nombre \\
\hline RAWVAWRNR-NH ${ }_{2}$ & $107-115 \mathrm{hLz}$ & Líder \\
\hline RKWVWWRNR-NH ${ }_{2}$ & {$\left[\mathrm{~K}^{108} \mathrm{~W}^{111}\right]$ 107-115 hLz } & Intermediario \\
\hline RKW(Ar)VWWRNR-NH ${ }_{2}$ & {$\left[\mathrm{~K}^{108} \mathrm{~W}-\mathrm{Ar}^{109} \mathrm{~W}^{111}\right] 107-115 \mathrm{hLz}$} & KW-Arilado ${ }^{109}$ \\
\hline RKWVW(Ar)WRNR-NH ${ }_{2}$ & {$\left[\mathrm{~K}^{108} \mathrm{~W}-\mathrm{Ar}^{111}\right] 107-115 \mathrm{hLz}$} & KW-Arilado ${ }^{111}$ \\
\hline RKWVWW(Ar)RNR-NH 2 & {$\left[\mathrm{~K}^{108} \mathbf{W}^{111} \mathrm{~W}-\mathrm{Ar}^{112}\right] 107-115 \mathrm{hLz}$} & KW-Arilado ${ }^{112}$ \\
\hline
\end{tabular}

Investigaciones previas han revelado que la membrana bacteriana es el blanco de estos péptidos y en ella ejercen su poder destructivo al interrumpir su continuidad, de formarla y crear poros. Este blanco terapéutico implica un difícil desarrollo de resistencia por parte de los microorganismos, constituyendo una virtud adicional de los péptidos KWArilados como nuevos agentes antimicrobianos.

La C2-arilación de indoles en Trp se llevó a cabo a través de la técnica de activación del enlace C-H, catalizada por Pd bajo irradiación por microondas (Ruiz-Rodríguez, 2010), como se muestra en la siguiente figura:
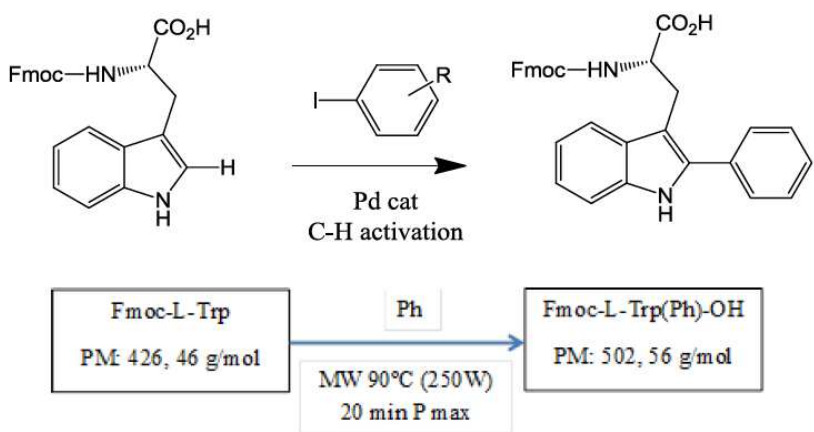

Por lo expuesto, de esta manera se logró potenciar la actividad antimicrobiana de KW-Arilado109, 20 veces frente a un microorganismo Gram negativo (E. coli). Asimismo, se aumentó la actividad antimicrobiana de KW-Arilado111 y KW-Arilado112, 70 veces 
frente a microorganismos Gram positivos (S. aureus, S. aureus metilino resistente, MRSA y S. epidermidis). La arilación del Trp 109 aumentó selectivamente la actividad del péptido frente a $E$. coli alcanzando una concentración inhibitoria mínima (CIM) de $20 \mu \mathrm{M}$, y ampliando su espectro antimicrobiano. Por otro lado, la arilación de los Trp111 o Trp112, aumentó selectivamente la actividad de los péptidos frente a los microorganismos Gram positivos alcanzando CIMs de 3,5 y $3 \mu \mathrm{M}$ frente a $S$. aureus, MRSA y $S$. epidermidis respectivamente. Las sustituciones en las posiciones 108 y 111 en el péptido intermediario aumentaron su actividad antimicrobiana 4 y 20 veces frente a microorganismos Gram (-) y Gram (+). Además, la arilación de los Trp aumentó 4 veces la actividad antimicrobiana de los péptidos alcanzando CIMs compatibles con una ventana terapéutica efectiva. La última modificación mejoró el perfil terapéutico de los péptidos, impulsando su candidatura como ingredientes farmacéuticos activos (IFAs) para renovar el arsenal de compuestos antimicrobianos.

La derivatización (arilación) de los Trp a los efectos de aumentar el poder de anclaje de los péptidos a la membrana bacteriana es una técnica novedosa que permitió el hallazgo de los KW-Arilados. Las CIMs obtenidas luego de la derivatización de los Trp, entran en una ventana terapéutica efectiva. Mediante microscopia electrónica, hemos demostrado que la membrana plasmática bacteriana es el blanco de los KW-Arilados; esto implica una baja posibilidad de generación de farmacorresistencia. Asimismo, este blanco terapéutico permitirá el uso de los D-isómeros de los KW-Arilados con el fin de aumentar su estabilidad y biodisponibilidad. Los $\mathrm{KW}$-Arilados puede ser incorporados en varias fórmulas (oral, tópica, inclusión en apósitos, inmovilización en implantes, prótesis y catéteres).

A modo de ejemplo, se muestran fotos obtenidas por microscopía electrónica de barrido que revelan el mecanismo de acción de los péptidos aril-Trp frente a Staphylococcus aureus. La foto de la izquierda representa el control, $0 \%$ de inhibición y a la derecha $\left[\mathrm{K}^{108} \mathrm{~W}^{111} \mathrm{~W}-\mathrm{Ar}^{112}\right]$ 107-115 hLz, 91\% de Inhibición.
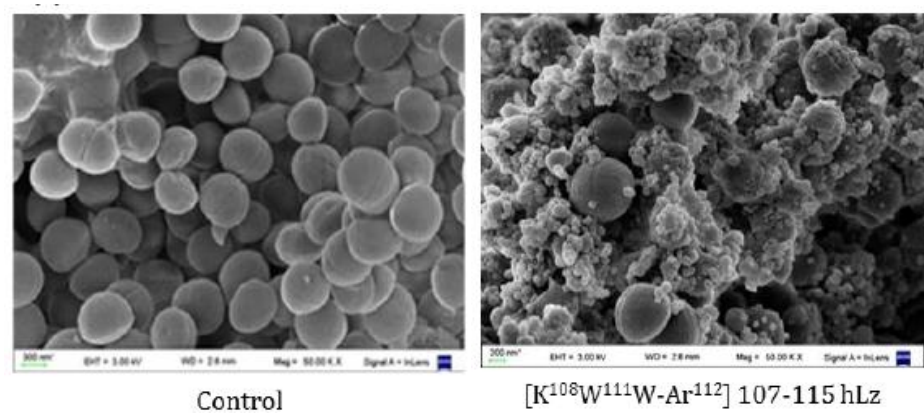

Esta significativa innovación podría abrir la puerta a nuevas transformaciones de este tipo, dirigidas a mejorar la acción farmacológica sin alterar la naturaleza anfipática existente del péptido, pero incrementando localmente la lipofilicidad de residuos 
específicos. De acuerdo a nuestro conocimiento del área, esta es la primera vez que la arilación de un triptófano se aplica en el desarrollo de un péptido con actividad antimicrobiana.

Estos péptidos poseen alta actividad y baja toxicidad, debido a que su blanco terapéutico es la membrana plasmática. Tal y como se mencionó anteriormente, existe una escasa probabilidad de generar resistencia. Considerando que estos péptidos causan daños en la membrana, pueden ser administrados en combinación con un antibiótico que posea un blanco intracelular y de esta forma promover un efecto sinérgico.

A modo de conclusión podemos expresar que los péptidos, ofrecen un potencial de crecimiento enorme como terapias futuras para el tratamiento de las necesidades médicas no cubiertas, anticipando un futuro promisorio para la terapéutica y el diagnóstico.

\section{Referencias bibliográficas}

O’Neill, J. (2016). Tackling drug-resistant infections globally: final report and recommendations. EE.UU: Nature Review Drug Discovery.

González, R., Albericio, F., Cascone, O. y lannucci, N. (2010). Improved antimicrobial activity of h-lysozyme (107-115) by rational Ala substitution. Journal of Peptide Science, 16, 424-429.

González, R., Mendive-Tapia, L., Pastrian, MB., Albericio, F., Lavilla, R., Cascone, O. y lannucci, N. (2016). Enhanced antimicrobial activity of a peptide derived from human lysozyme by arylation of its tryptophan residues. Journal of Peptide Science, 22, 123-128.

lannucci, N., Curto, L., Albericio, F., Cascone, O. y Delfino, J. (2013). Structural Glance Into a Novel Anti-Staphylococcal Peptide. Biopolymers, Peptide Science, 102, 49-57.

lannucci, N., González, R., Cascone, O. and Albericio, F. (2011). Novel strategy for designing antimicrobial peptides: an answer to the development of drug resistance. Méndez- Vilas (ed.). Science against microbial pathogens: communicating current research and technological advances (pp. 961-967). EE.UU.: Formatex.

Kates, S. A. and Albericio, F. (2000). Solid Phase Synthesis. A Practical Guide. Eds. Marcel Dekker: New York. 
Kraus, D. and Peschel, A. (2006). Molecular Mechanisms of Bacterial Resistance to Antimicrobial Peptides. AA.VV. Current Topics in Microbiology and Immunology (231-250). EE.UU.: Springer.

Preciado, S., Mendive-Tapia, L., Fernando Albericio, F. and Rodolfo Lavilla, R. (2013). Synthesis of C-2 Arylated Tryptophan Amino Acids and Related Compounds through Palladium-Catalyzed C-H Activation. Journal of Organic Chemistry, 78, 8129-8135.

Ruiz-Rodríguez, J., Albericio, F. y Lavilla, R. 2010. Postsynthetic Modification of Peptides: Chemoselective C-Arylation of Tryptophan Residues. Chemistry, A European Journal, 16,1124-1127. 